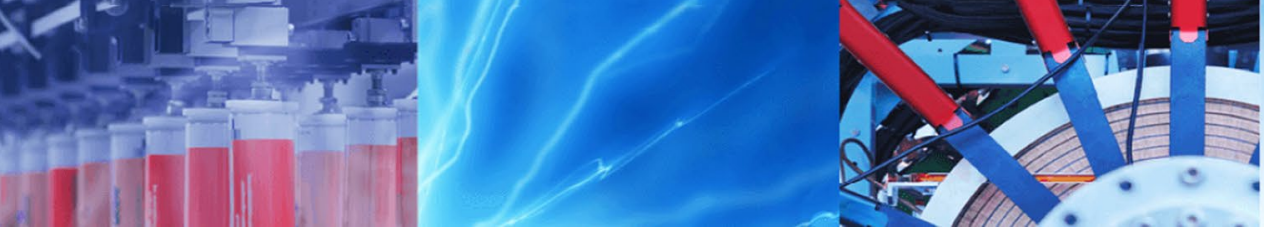

Research Article

\title{
Real-time emulation of photovoltaic energy using adaptive state feedback control
}

\author{
Mustapha Alaoui $^{1}$ (D) Hattab Maker ${ }^{1} \cdot$ Azeddine Mouhsen $^{3} \cdot$ Hicham Hihi $^{2}$
}

Received: 13 October 2019 / Accepted: 18 February 2020 / Published online: 27 February 2020

(c) Springer Nature Switzerland AG 2020

\begin{abstract}
The current paper presents an experimental validation of photovoltaic (PV) source emulation using a real-time dSpace controller. The PV source emulator is a nonlinear power electronic device used to provide in real-time the electrical behavior of PV panels by tracking the PV current-voltage (I-V) characteristic. It aims to deliver nearly the same current and voltage as an actual PV module without depending on atmospheric conditions. This innovative tool is able to aid researchers in PV systems to perform their tests and measurements at the desired weather parameters without time, space and cost constraints. The proposed PV emulator is based on a simple and efficient adaptive state feedback control that ensures good accuracy and high dynamic response compared to the existing commercial PV emulators based on the programmable power supply, which improves significantly the static and dynamic performances of existing PV emulators.
\end{abstract}

Keywords Adaptive state feedback control · dSpace controller $\cdot$ Real-time emulation $\cdot$ PV emulator $\cdot$ PV characteristics

\section{Introduction}

For decades, renewable and sustainable energies have become one of the most important topics nowadays. The impact of conventional power resources on the environment is being more and more hazardous. As a matter of fact, research and development of novel green and sustainable solutions have interested many researchers and manufacturers [1]. Among these new alternatives, there is photovoltaic solar energy which has received a great interest in recent years. The research on PV energy has trended essentially towards the PV optimization using Maximum Power Point Tracking (MPPT) algorithms and the solar connected inverters for grid injection. However, the development of these fields requires mainly real-time experimentation without depending on weather conditions such as temperature ( $\mathrm{T}$ ) and solar irradiance $(\mathrm{G})$ [2]. Besides, the cost of real PV panels is actually expensive and a large area is required by PV modules. For those reasons, PV researchers though to invent a laboratory equipment so-called PV emulator able to behave electrically as an actual PV source. This innovative device has to mimic accurately the PV panels and reproduce nearly the same current and voltage. It should not depend on atmospheric conditions and it has to allow choosing the desired numerical weather conditions in which the experiment would be carried out [1-6].

In the literature review, many researchers are being interested in PV source emulators, all these researchers aim to satisfy the PV emulation requirements which are basically the accuracy, speed, use easiness and efficiency [3]. The majority of them have used switched-mode power supplies that are more efficient than linear regulators $[2$, 7], especially the DC-DC buck converter which is the simplest power converter topology [8-11]. Furthermore, in

\footnotetext{
$\triangle$ Mustapha Alaoui, mu.alaoui@uhp.ac.ma; Hattab Maker, hattabmaker@gmail.com; Azeddine Mouhsen, az.mouhsen@gmail.com; Hicham Hihi, hicham.hihi@usmba.ac.ma | ${ }^{1}$ Interdisciplinary Laboratory of Applied Sciences, National School of Applied Sciences, Hassan First University, Berrechid, Morocco. ${ }^{2}$ Laboratory of Engineering, Systems and Applications, National School of Applied Sciences, Sidi Mohamed Ben Abdellah University, Fez, Morocco. ${ }^{3}$ Laboratory of Radiation-Matter and Instrumentation, Sciences and Technologies Faculty, Hassan First University, Settat, Morocco.
} 
the control part, the direct referencing methods with the proportional integrator (PI) regulator are the most used control strategy of existing PV emulators thanks to their simplicity and easiness $[9,10,12-18]$. However, due to the nonlinearity of the PV characteristics, the conventional control techniques based on linear compensators cannot guaranty the required performances of the PV emulation [2]. The stability of the closed-loop could be affected while using classical control especially when the good dynamic response is intended $[2,19]$. Moreover, the dynamic performances are highly needed for PV emulators for testing, for instance, MPPT algorithms. Nevertheless, the commercial PV emulators based on programmable power supply have a poor dynamic response between 10 and $100 \mathrm{~ms}$ [2]. That is why the present paper aims to deal with those problems by improving the static and dynamic performances of the PV emulators and ensuring good stability and accuracy. The proposed PV system makes significant contributions in terms of accuracy and dynamic response compared to the existing solutions and ensures high emulation performances using a simple control strategy, unlike many researches that have used iterative solutions such as hill-climbing method, resistance comparison method, resistance line method [2] and many other strategies that need an iterative cycles number to reach the required operating point [2]. The developed PV emulator is based essentially on an adaptive state feedback controller which regulates both the current and voltage of the PV emulator circuit and takes into consideration the nonlinearity of the PV characteristics. This controller is implemented in the dSpace platform to ensure real-time control.

This study is organized as follows: the materials and system description are presented in section II, while the proposed method is described in section III. The experimental results are given in section IV, and finally the analysis and discussion are provided in section $\mathrm{V}$.

\section{Materials and system components}

The proposed system is based essentially on two parts, the power part which consists of the DC-DC buck converter, and the control part which is based on the dSpace 1104 board. This calculator contains the implementation of the PV characteristics of the desired PV module to be emulated beside the state feedback controller. The PV characteristics are implemented using Look-Up-Table (LUT) technique which ensures high speed and does not require an additional algorithm for solving the mathematic PV model [20-23]. The LUT constitutes the reference generator that determines the operating point of the system and delivers, as a result, the voltage reference to the state feedback controller.

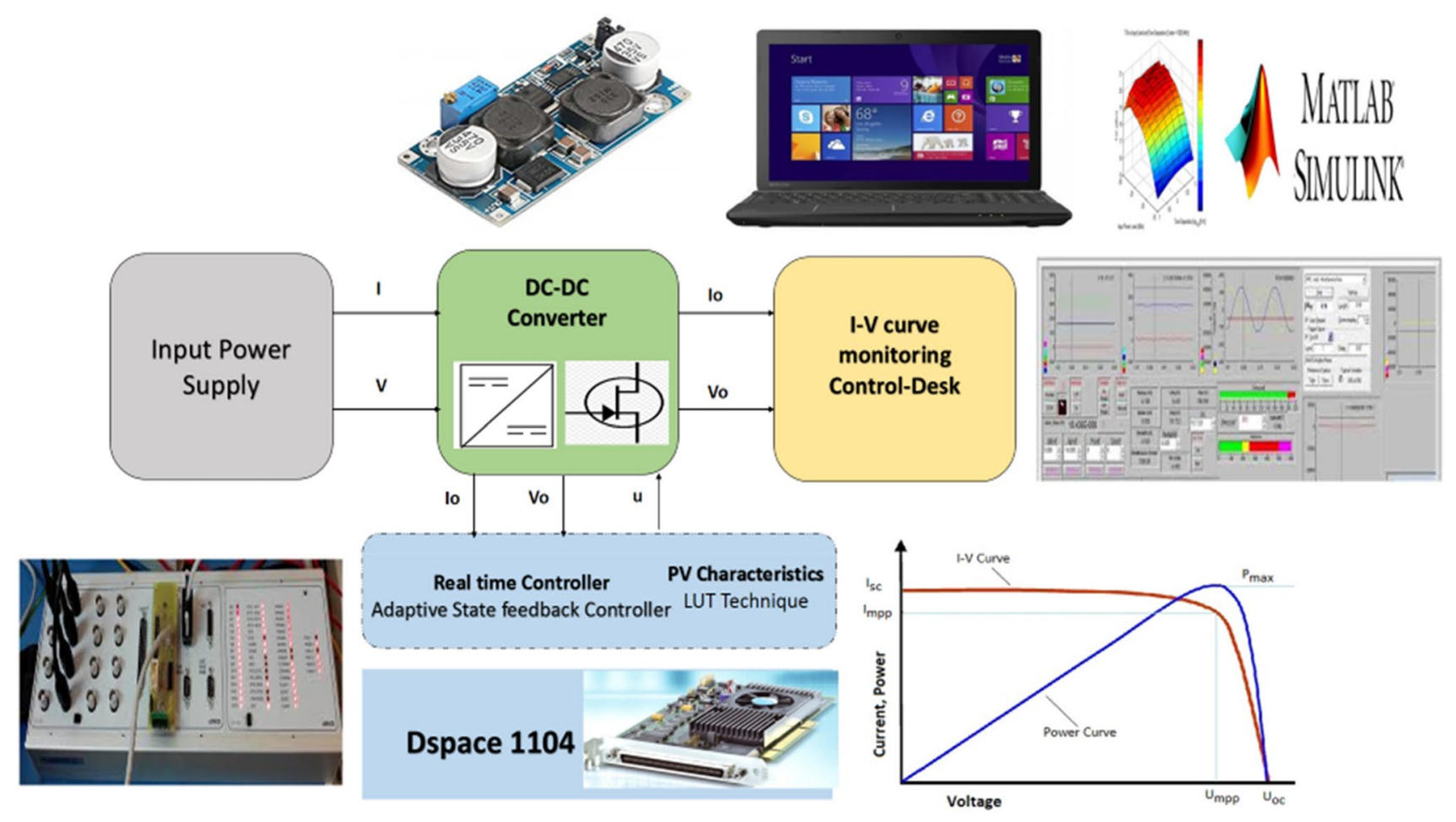

Fig. 1 Overall descriptive structure of the proposed PV source emulator 
Table 1 Parameters of the PV emulator and LA30-12S LORENTZ PV module

\begin{tabular}{ll}
\hline Variable & Value \\
\hline Input voltage Vi (Vdc) & $30 \mathrm{~V}$ \\
Inductor L & $1.5 \mathrm{mH}$ \\
Capacitor C & $10 \mu \mathrm{F}$ \\
Switching frequency f & $20 \mathrm{kHz}$ \\
Peak power rated & $30 \mathrm{~W}$ \\
Short circuit current Isc & $1.9 \mathrm{~A}$ \\
Open circuit voltage Voc & $21 \mathrm{~V}$ \\
Maximum power point current Impp & $1.7 \mathrm{~A}$ \\
Maximum power point voltage Vmpp & $17.5 \mathrm{~V}$ \\
Temperature coefficient of Voc: $\mathrm{kv}$ & $-60.5 \mathrm{mV} /{ }^{\circ} \mathrm{C}$ \\
Temperature coefficient of Isc: $\mathrm{ki}$ & $1.8 \mathrm{~mA} /{ }^{\circ} \mathrm{C}$ \\
Temperature coefficient of power: $\mathrm{kp}$ & $-0.38 \% /{ }^{\circ} \mathrm{C}$ \\
Number of Cells in series Ns & 33 \\
\hline
\end{tabular}

The latter tracks accurately this reference and deliver as a result the duty cycle that will be used by the pulse width modulation (PWM) bloc of the dSpace card to generate the control signal of the converter transistor. The Control Desk platform is used for real-time monitoring of the PV emulator outputs as well as the variation of the climatic parameters and the controller gains. Figure 1 illustrates the overall architecture of the PV emulator.

The parameters of the PV emulator and the chosen PV module are given in Table 1.

\section{Proposed method of control}

The adaptive state feedback controller is used to track faithfully the I-V characteristic of the PV module, this controller permits regulating both the current and voltage, unlike the PID controller which utilizes either current or voltage feedback. Besides, for the aim of ensuring good accuracy and I-V curve tracking, an Integrator is used in the controller expression so that the static error converges to zero. Moreover, the controller gains are adjusted according to the desired speed, accuracy and $\mathrm{I}-\mathrm{V}$ curve region.

The DC-DC buck converter is used in this application as shown in Fig. 2 controlled by the dSpace board.

The augmented state-space model of the DC-DC buck converter is written as:

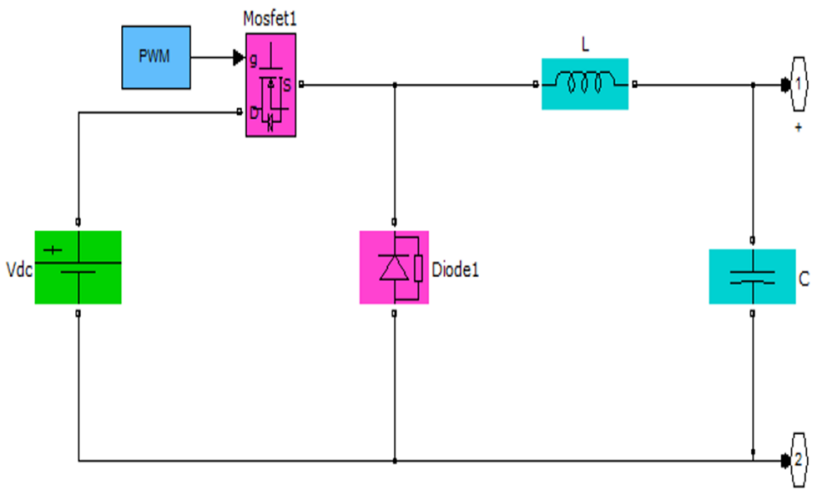

Fig. 2 DC-DC buck converter

$\left\{\begin{array}{l}\frac{d x 1}{d t}=\frac{x_{2}}{C}-\frac{x_{1}}{R C} \\ \frac{d x 2}{d t}=-\frac{x_{1}}{L}+\frac{V d c}{L} u \\ \frac{d x 3}{d t}=\text { Vref }-x_{1}\end{array}\right.$

with $\times 1=V c$ the capacitance voltage, $x 2=i L$ the self-current and $\times 3=\frac{1}{s}(V$ ref $-V c)$, the integral of the error between the voltage reference $V$ ref delivered by the reference generator and the output voltage Vc.

The augmented simplified state-space model can be expressed as:

$\left\{\begin{array}{l}\dot{x}=A x+B u \\ y=C x\end{array}\right.$

with $x=\left(\begin{array}{c}V c \\ i_{L} \\ \frac{1}{s}(V r e f-V c)\end{array}\right) \quad A=\left(\begin{array}{ccc}\frac{-1}{R C} & \frac{1}{C} & 0 \\ \frac{-1}{L} & 0 & 0 \\ -1 & 0 & 0\end{array}\right)$

$$
B=\left(\begin{array}{c}
0 \\
\frac{V d c}{L} \\
0
\end{array}\right) \quad C=\left(\begin{array}{lll}
1 & 0 & 0
\end{array}\right)
$$

The control law $\mathrm{u}$ has the following form:

$u=-k 1 V c-k 2 I L-\frac{k 3}{s}(V r e f-V c)$

where $k 1, k 2$ and $k 3$ are the real positive gains of the state feedback controller and $\mathrm{s}$ is the Laplace operator.

For the closed-loop system:

$\dot{x}=A x+B u=(A-B K) x$

with $K=(k 1, k 2, k 3)$ 
Table 2 Controller gains values

\begin{tabular}{lll}
\hline Gain & I-V curve region & \\
\cline { 2 - 3 } & $\begin{array}{l}\text { Constant current region } \\
\mathrm{R} \leq \mathrm{Vmpp} / \mathrm{Impp}\end{array}$ & $\begin{array}{l}\text { Constant voltage region } \\
\mathrm{R}>\mathrm{Vmpp} / \mathrm{mpp}\end{array}$ \\
\hline $\mathrm{k} 1$ & 0.01 & 1 \\
$\mathrm{k} 2$ & 0.2 & 1.5 \\
$\mathrm{k} 3$ & 1.4 & 10 \\
\hline
\end{tabular}

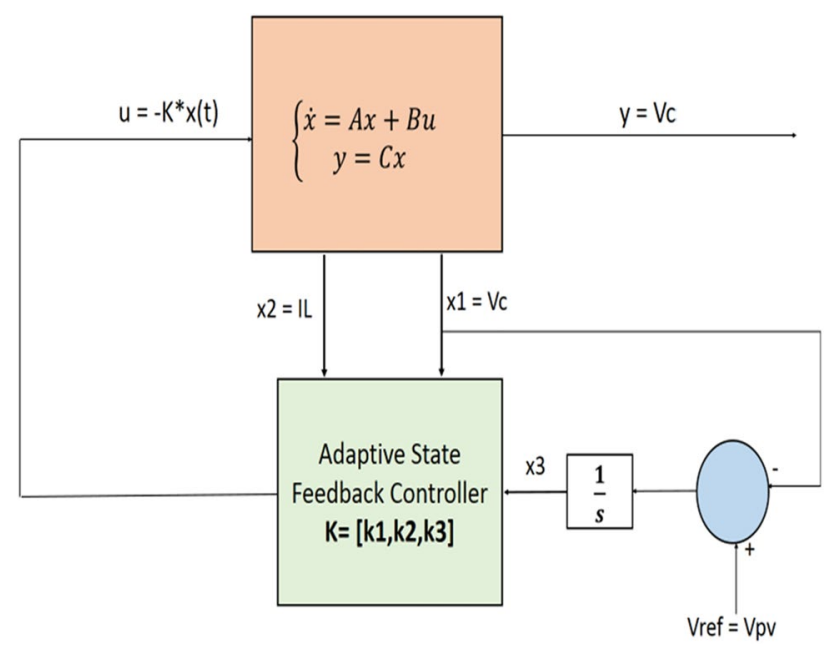

Fig. 3 The adaptive state feedback controller

$A-B K=\left(\begin{array}{ccc}\frac{-1}{R C} & \frac{1}{C} & 0 \\ \frac{-1-V d c * k 1}{L} & -\frac{V d c * k 2}{L} & -\frac{V d c * k 3}{L} \\ -1 & 0 & 0\end{array}\right)$
According to the I-V curve region, either a constant current region or constant voltage region, the controller gains are twisted in order to deal with the nonlinearity of the I-V curve and have thereby more accuracy and stability. Indeed, the PV current and voltage dynamics are not the same in the whole I-V curve, they vary depending on the operating point position. In the constant current region, the PV current is almost constant while the PV voltage varies strongly, and in the constant voltage region, the PV voltage is nearly constant while the PV current changes intensively. Therefore, the controller gains take into consideration this particularity and changes according to the I-V curve zone as shown in Table 2. The controller parameters have been chosen so that the closed-loop matrix (A-BK) stays always Hurwitz stable, then they have been twisted practically using trial and error method by the Control Desk interface until finding the ones giving the desired performances of the system.

The synoptic schema in Fig. 3 illustrates the adaptive state feedback structure.

\section{Experimental results}

The experimental setup of the PV emulator is depicted in Fig. 4, it is composed of the control desk interface, hardware dSpace card where the adaptive state feedback controller is implemented, the DC-DC buck converter, the signal conditioning and sensing system used to measure the output current and voltage of the PV emulator and adapt it to the dSpace interface, beside the power part which

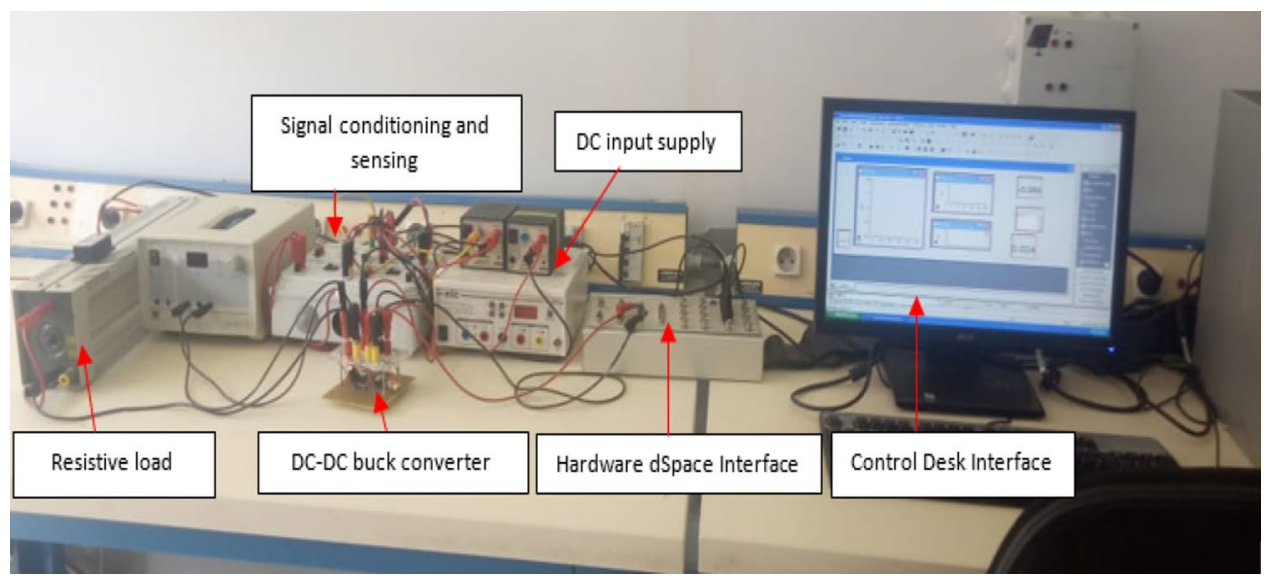

Fig. 4 Experimental setup of the proposed PV source emularor 

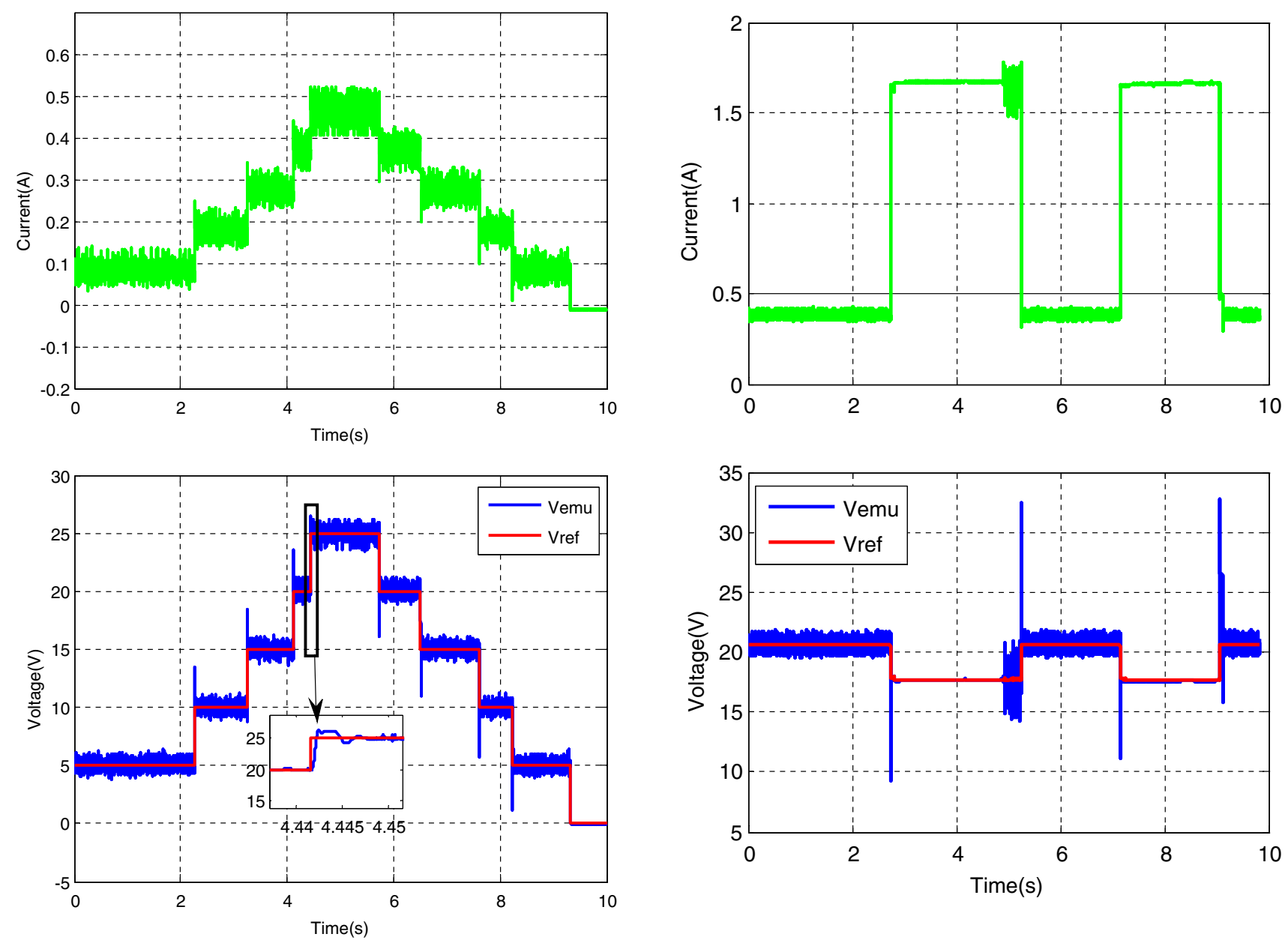

Fig. 6 PV emulator under resistance load variation

Fig. 5 Output current and voltage of the proposed circuit for $\mathrm{R}=50 \Omega$

includes the DC-DC buck converter, the DC input supply and the resistive load.

For the purpose of making sure that the proposed controller tracks with accuracy the voltage reference, we have subjected the circuit to successive voltage reference steps and we have measured the output current and voltage as given in Fig. 5.

The dynamic performances are shown in Fig. 6 where the PV emulator is subjected to the load variation. The main objective is to show the ability of the proposed PV emulator to generate the same current and voltage as an actual PV module. The transient part is zoomed-in as shown in Fig. 7.

The static performances are assessed in Fig. 8 where different operating points are measured. The resistance 

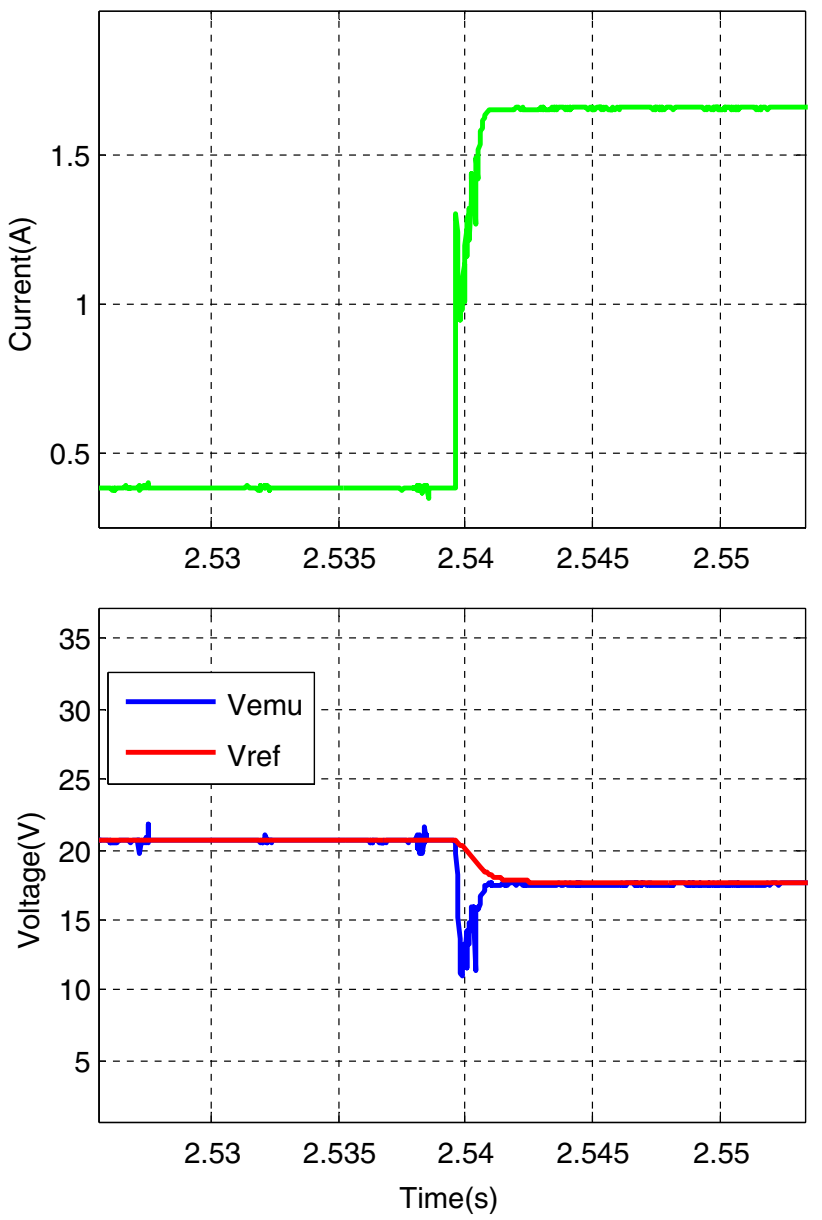

Fig. 7 PV emulator under variation of the resistance load
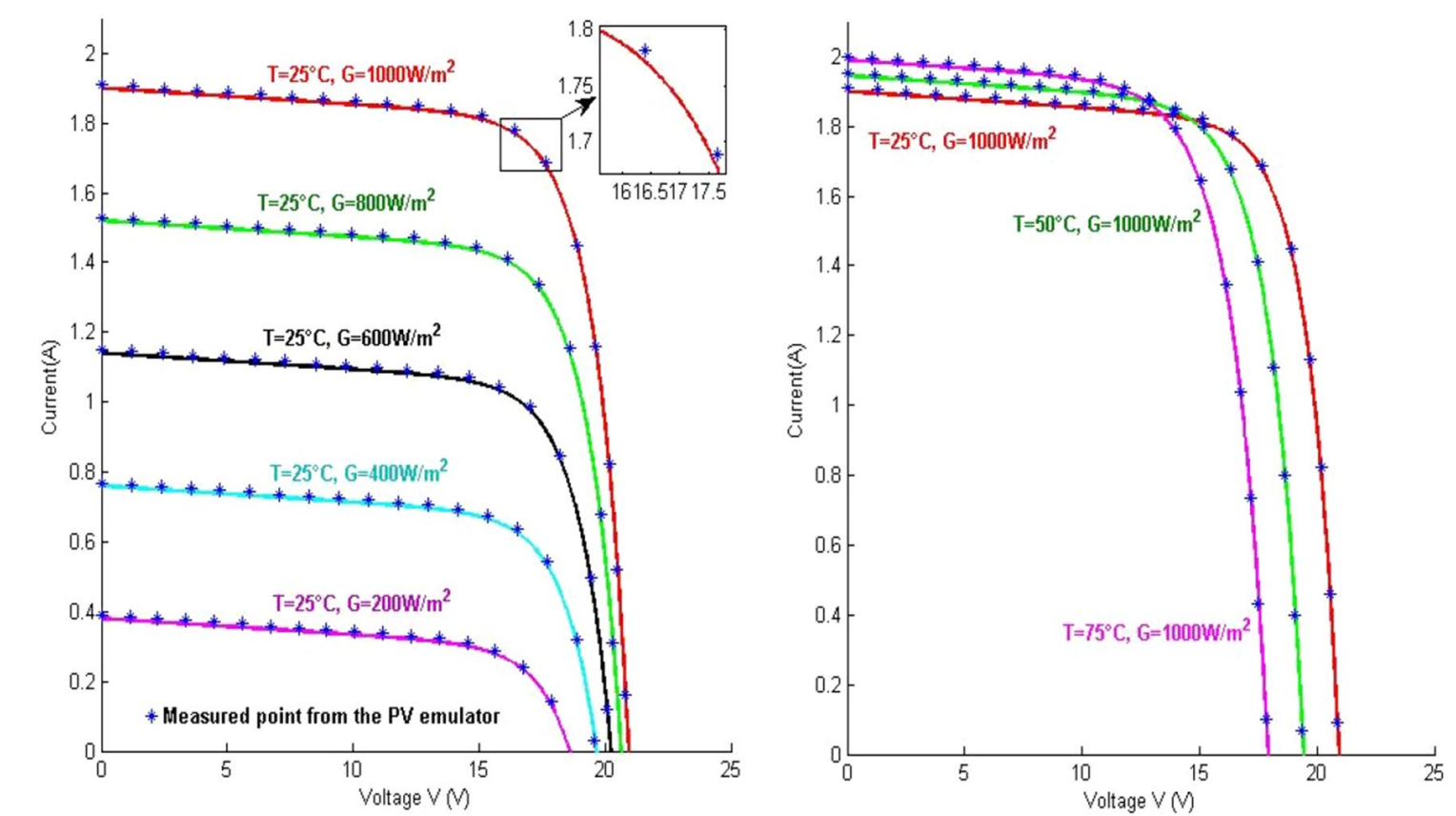

Fig. 8 I-V characteristic curves of the PV module and the PV emulator for different solar irradiances and temperatures load has been changed so that the whole I-V characteristic curve can be covered. Besides, the solar insolation and ambient temperature have been changed numerically to sweep different weather parameters and deliver therefore approximately the same PV characteristics as the PV module technical datasheet ones.

\section{Discussion}

As displayed in Figs. 5, 6 and 7, the proposed PV emulator circuit is able to track accurately the voltage reference, it is endowed with a good dynamic response since the settling time does not exceed $2 \mathrm{~ms}$. Besides, the proposed system remains stable and accurate while varying the resistance value thanks to the adaptive state feedback controller. Moreover, according to Fig. 8, it is obvious that the static performances of the system are very high since the static error does not exceed $5 \%$ for the whole I-V curve, the proposed system has good adaptability to the environmental parameters variation of temperature and irradiance. It can generate nearly the same current and voltage of the PV module for different values of solar irradiance and temperature. It is up to the user thus to provide the datasheet parameters of the desired PV module to emulate, then the proposed system can follow the corresponding PV characteristic.

SN Applied Sciences

a SPRINGer NAtURE journal 


\section{Conclusion}

This paper presents some experimental results of the PV source emulator used to act as an actual PV module and provide thus similar I-V characteristic curves. An adaptive state feedback controller implemented in dSpace board has been used to ensure real-time control as well as good static and dynamic performances. The given experimental results showed that the proposed PV emulator can achieve a good dynamic response and have a better bandwidth compared to the existing commercial PV emulators based on programmable power supply. Besides, the accuracy is not affected while changing the resistance load and thus the operating point of the system. It has been proven that the realized power circuit can sweep the whole I-V curve for different values of solar irradiance and temperature. Future works will focus on the emulation of the partial shading conditions and the PV array configurations, as well as the implementation of this simplified control technique in low-cost platforms such as a microcontroller, DSPIC... in order to reduce the total cost of the developed PV emulator, so that it can be commercialized in the future.

\section{Compliance with ethical standards}

Conflict of interest On behalf of all authors, the corresponding author states that there is no conflict of interest.

\section{References}

1. Di Piazza MC, Vitale G (2013) Photovoltaic sources: modeling and emulation. Springer, London

2. Ayop R, Tan CW (2017) A comprehensive review on photovoltaic emulator. Renew Sustain Energy Rev 80:430-452. https://doi. org/10.1016/j.rser.2017.05.217

3. Ram JP, Manghani H, Pillai DS, Babu TS, Miyatake M, Rajasekar N (2018) Analysis on solar PV emulators: a review. Renew Sustain Energy Rev 81:149-160. https://doi.org/10.1016/j. rser.2017.07.039

4. Ayop R, Tan CW (2019) Rapid prototyping of photovoltaic emulator using buck converter based on fast convergence resistance feedback method. IEEE Trans Power Electron 34(9):8715-8723. https://doi.org/10.1109/TPEL.2018.2886927

5. Moussa I, Khedher A (2019) Photovoltaic emulator based on PV simulator RT implementation using XSG tools for an FPGA control: theory and experimentation. Int Trans Electr Energy Syst 29(8):e12024. https://doi.org/10.1002/2050-7038.12024

6. Alaoui M, Maker H, Mouhsen A (2018) PV emulator based on interleaved buck converter using adaptive PI controller. In: International meeting on advanced technologies in energy and electrical engineering (IMAT3E'18), Fez, Morocco
7. Schofield DMK, Foster MP, Stone DA (2011) Low-cost solar emulator for evaluation of maximum power point tracking methods. Electron Lett 47(3):208-209. https://doi.org/10.1049/ el.2010.2930

8. González-Medina R, Patrao I, Garcerá G, Figueres E (2014) A lowcost photovoltaic emulator for static and dynamic evaluation of photovoltaic power converters and facilities. Prog Photovolt Res Appl 22(2):227-241. https://doi.org/10.1002/pip.2243

9. Piazza MCD, Pucci M, Ragusa A, Vitale G (2010) A grid-connected system based on a real time PV emulator: design and experimental set-up. In: IECON 2010-36th annual conference on IEEE industrial electronics society, pp 3237-3243. https://doi. org/10.1109/iecon.2010.5675055

10. Piazza MCD, Pucci M, Ragusa A, Vitale G (2010) Analytical versus neural real-time simulation of a photovoltaic generator based on a DC-DC converter. IEEE Trans Ind Appl 46(6):2501-2510. https://doi.org/10.1109/TIA.2010.2072975

11. Alaoui M, Maker $H$, Mouhsen A (2019) An accurate photovoltaic source emulator with high-bandwidth using a backstepping controller. In: 2019 4th world conference on complex systems (WCCS), pp 1-6. https://doi.org/10.1109/icocs .2019 .8930786

12. Ickilli D, Can H, Parlak KS (2012) Development of a FPGA-based photovoltaic panel emulator based on a DC/DC converter. In: 2012 38th IEEE photovoltaic specialists conference, pp 001417001421. https://doi.org/10.1109/pvsc.2012.6317863

13. Roncero-Clemente C, Romero-Cadaval E, Minambres VM, Guerrero-Martinez MA, Gallardo-Lozano J (2013) PV array emulator for testing commercial PV inverters. Electron Electr Eng. https ://doi.org/10.5755/j01.eee.19.10.5899

14. Martin-Segura G, Lopez-Mestre J, Teixido-Casas M, SudriaAndreu A (2007) Development of a photovoltaic array emulator system based on a full-bridge structure. In: 2007 9th international conference on electrical power quality and utilisation, Barcelona, Spain, pp 1-6. https://doi.org/10.1109/epqu.2007.44241 65

15. Zhuo Z, Zhang J, Sun H, Wang G, Hu X, Zhao S (2010) Research on photovolta array emulator system based on a novel zerovoltage zero-current switching converter. In: 2010 Asia-Pacific power and energy engineering conference, pp 1-4. https://doi. org/10.1109/appeec.2010.5448919

16. Balato $M$, Costanzo L, Gallo D, Landi C, Luiso M, Vitelli M (2016) Design and implementation of a dynamic FPAA based photovoltaic emulator. Sol Energy 123:102-115. https://doi. org/10.1016/j.solener.2015.11.006

17. Masashi S, Naoki Y, Muneaki I (2012) Development of photovoltaic cell emulator using the small scale wind turbine. In: 2012 15 th international conference on electrical machines and systems (ICEMS), pp 1-4

18. Algaddafi A, Brown N, Gammon R, Altuwayjiri SA (2015) Effect of $P V$ array emulator on power quality of PV inverter compared to a real PV array. In: 2015 3rd international renewable and sustainable energy conference (IRSEC), pp 1-6. https://doi.org/10.1109/ irsec.2015.7455099

19. Ayop R, WeiTan C, SiongLim C (2018) The resistance comparison method using integral controller for photovoltaic emulator. Int J Power Electron Drive Syst 9(2):820. https://doi.org/10.11591/ ijpeds.v9.i2.pp820-828

20. Koutroulis E, Kalaitzakis K, Tzitzilonis V (2009) Development of an FPGA-based system for real-time simulation of photovoltaic modules. Microelectron J 40(7):1094-1102. https://doi. org/10.1016/j.mejo.2008.05.014 
21. Jin S, Zhang D (2016) A simple control method of open-circuit voltage for the FPGA-based solar array simulator. In: 2016 IEEE international conference on power and renewable energy (ICPRE), pp 209-216. https://doi.org/10.1109/icpre.2016.78712 02

22. Zhang W, Kimball JW (2018) DC-DC converter based photovoltaic simulator with a double current mode controller. IEEE Trans Power Electron 33(7):5860-5868. https://doi.org/10.1109/ TPEL.2017.2742461
23. Zhao J, Kimball JW (2012) A digitally implemented photovoltaic simulator with a double current mode controller. In: 2012 twenty-seventh annual IEEE applied power electronics conference and exposition (APEC), pp 53-58. https://doi.org/10.1109/ apec.2012.6165798

Publisher's Note Springer Nature remains neutral with regard to jurisdictional claims in published maps and institutional affiliations. 